\title{
Ramosetron Does Not Reduce the Analgesic Efficacy of Tramadol after Gynecological Laparoscopic Surgery
}

\author{
Yanghyun Kim (D) and Sungwoo Kang \\ Department of Anesthesia and Pain Medicine, National Cancer Center, Goyang, Republic of Korea \\ Correspondence should be addressed to Yanghyun Kim;11466@ncc.re.kr
}

Received 16 April 2019; Accepted 1 July 2019; Published 9 July 2019

Academic Editor: Kurt Ruetzler

Copyright (c) 2019 Yanghyun Kim and Sungwoo Kang. This is an open access article distributed under the Creative Commons Attribution License, which permits unrestricted use, distribution, and reproduction in any medium, provided the original work is properly cited.

\begin{abstract}
Background. The effect of ramosetron on the analgesic action of tramadol is not well known when ramosetron is added to intravenous-tramadol patient-controlled analgesia (PCA) and infused continuously. The aim of this randomized noninferiority study was to evaluate the effects of ramosetron on the analgesic action of tramadol when it is administered simultaneously in women undergoing laparoscopic gynecology who are receiving tramadol via IV PCA. Method. This study used a prospective, randomized, controlled, noninferiority clinical trial design and compared the analgesic effect of tramadol plus ramosetron with that of tramadol only. A total of 110 postoperative patients, who were using IV PCA tramadol, were randomly assigned either to a group receiving ramosetron (group $\mathrm{R}, \mathrm{n}=49$ ) or to a group that received the same volume of normal saline continuously (group $\mathrm{N}, \mathrm{n}=51$ ). Observation time points for cumulative tramadol consumption were the first hour, and every $4 \mathrm{~h}$ up to $12 \mathrm{~h}$ and then $24 \mathrm{~h}$ after surgery. Pain intensity at rest and during movement, coughing, and nausea scores, the analgesic and antiemetic doses used, side effects, and patient satisfaction were evaluated 1 and $24 \mathrm{~h}$ after surgery. Results. Groups $\mathrm{R}$ and $\mathrm{N}$ received, respectively, $88 \pm 55$ vs. $79 \pm 42 \mathrm{mg}$ tramadol $(\mathrm{P}=0.511)$ after $1 \mathrm{~h}, 211 \pm 122 \mathrm{vs.} 198 \pm 109 \mathrm{mg}$ cumulative tramadol $(\mathrm{P}=0.610)$ after $4 \mathrm{~h}, 244 \pm 150$ vs. $231 \pm 134 \mathrm{mg}$ cumulative tramadol $(\mathrm{P}=0.793)$ after $8 \mathrm{~h}, 250 \pm 156$ vs. $247 \pm 153 \mathrm{mg}$ cumulative tramadol $(\mathrm{P}=0.972)$ after $12 \mathrm{~h}$, and $294 \pm 190$ vs. $284 \pm 178 \mathrm{mg}$ cumulative tramadol $(\mathrm{P}=0.791)$ after $24 \mathrm{~h}$, postsurgery. Tramadol plus ramosetron was shown to be not significantly inferior to tramadol alone in alleviating the postoperative pain. Conclusions. The analgesic effect of tramadol combined with ramosetron was found to be noninferior to tramadol alone for postoperative PCA after laparoscopic gynecologic surgery.
\end{abstract}

\section{Introduction}

Tramadol in patient-controlled analgesia (PCA) is known to provide effective analgesia for acute pain following major surgery $[1,2]$. Tramadol has a dual mechanism of action, which acts as a weak opioid agonist and an inhibitor of reuptake of serotonin and norepinephrine [3]. Tramadol has several advantages over other opioids, including a low probability of cardiovascular or respiratory depression, urinary retention, addiction, and reduced gastrointestinal mobility [4]. However, tramadol has been reported to cause relatively more nausea and vomiting, which limits its use [5]. Due to this reason, the antiemetic drug, serotonin receptor antagonist, is often coadministered or mixed with tramadol in postoperative PCA for preventing postoperative nausea and vomiting (PONV). However, the combination of drugs can cause undesirable effects. Several studies have reported that ondansetron, a $5-\mathrm{HT}_{3}$ serotonin receptor antagonist, can reduce the analgesic effect of tramadol due to drug interaction effects [6-8]. Randomized controlled studies evaluating the effect of ramosetron on the analgesic effect of tramadol are lacking. Kim et al. reported that a single, $0.3 \mathrm{mg}$ ramosetron injection at anesthesia induction did not reduce the analgesic effect of tramadol [9]. However, in clinical settings, patients may receive multiple doses of ramosetron or infusion continuously. Therefore, the aim of this randomized noninferiority study was to evaluate the effects of ramosetron on the analgesic action of tramadol when it is administered simultaneously in women undergoing laparoscopic gynecology who are receiving tramadol via IV PCA. 
The primary outcome in this study was the group difference in cumulative dose of tramadol $1,4,8,12$, and 24 h postoperatively. The secondary outcomes included pain score, incidence of nausea and vomiting, total rescue antiemetic drug use, patients' satisfaction, and frequency of side effects during the $24 \mathrm{~h}$ postoperative period.

\section{Materials and Methods}

This study was approved by the Institutional Review Board of the National Cancer Center (IRB no. NCCCTS 11599) and was registered with the Korean Clinical Trials Registry (CRiS, http://cris.nih.go.kr, KCT 0001750). After obtaining written informed consent, we enrolled 110 female patients between 18 and 64 years of age with an American Society of Anesthesiologists (ASA) physical status of I or II, who were undergoing laparoscopic gynecologic surgery. Patients who were unable to use the intravenous PCA device unassisted, had used other antiemetics or steroids in the $24 \mathrm{~h}$ prior to surgery, were on antidepressants, had a known allergy to tramadol or ramosetron, or had epilepsy, alcoholism, obesity (body mass index $>35 \mathrm{~kg} / \mathrm{m}^{2}$ ), severe renal or hepatic insufficiency, or severe cardiopulmonary disease were excluded. On the day before surgery, patients were familiarized with the IV PCA device (Hospira Gemstar Infusion Pump, Abbott Laboratories, USA) and the $100 \mathrm{~mm}$ visual analog scale (VAS) $(0 \mathrm{~mm}=$ no pain, $100 \mathrm{~mm}=$ worst imaginable pain $)$ for evaluating postoperative pain intensity.

This study used a randomized, placebo-controlled design. Patients were randomized into two groups according to the random selection of sealed envelopes: group $\mathrm{R}$ (tramadol and ramosetron) or group $\mathrm{N}$ (tramadol and saline). In group $\mathrm{R}$, PCA pumps were filled with $900 \mathrm{mg}$ tramadol $(9 \mathrm{mg} / \mathrm{mL})$ mixed with $0.6 \mathrm{mg}$ ramosetron diluted to $100 \mathrm{~mL}$ with $0.9 \%$ saline. In group $\mathrm{N}$, the PCA pump was filled with tramadol $(9 \mathrm{mg} / \mathrm{mL})$ in saline solution.

Endotracheal intubation was performed and intermittent positive ventilation was provided to maintain an EtCO2 of 35-40 mmHg. Anesthesia was maintained with continuous, target-controlled infusion of propofol and remifentanil infusion to maintain the bispectral index at 40-50. At the beginning of fascia closure, all patients were connected to a PCA device and received a loading dose of $27 \mathrm{mg}$ tramadol. The study drugs were prepared by a nurse blinded to the study treatment. The PCA device was set with a demand dose of $9 \mathrm{mg}$ (at $5 \mathrm{~min}$ intervals) and a daily maximal dose of $900 \mathrm{mg}$. No basal infusion was set. At the beginning of skin closure, propofol and remifentanil were stopped and the neuromuscular blockade was reversed using pyridostigmine with glycopyrrolate. The total amounts of remifentanil and propofol infused during anesthesia were recorded.

At the PACU, for any patients who did not experience satisfactory relief from pain following the above PCA regimen, a single $50 \mu \mathrm{g}$ IV dose of fentanyl was added and the total amounts of fentanyl were recorded. If the VAS score was > 4 after discharge from the recovery room, $30 \mathrm{mg}$ Ketorolac tromethamine (Trolac ${ }^{\circledR}$ ) was administered. For patients with severe nausea and vomiting, an IV dose of metoclopramide was injected and the total amounts of metoclopramide used were recorded. Pain intensity was evaluated on a $100 \mathrm{~mm}$ VAS (0 $\mathrm{mm}=$ no pain, $100 \mathrm{~mm}=$ worst imaginable pain $). A$ single anesthesiologist evaluated pain intensity at rest, during movement, during coughing, nausea (using a 4-point scale: 0 $=$ no nausea $1=$ mild nausea, no request for pharmacological rescue; 2 = moderate nausea, request for pharmacological rescue; and 3 = severe nausea-resistant pharmacological therapy) [10], vomiting (presence or absence), and 1 and $24 \mathrm{~h}$ postoperatively. Observation time points for tramadol consumption were the first hour, and every $4 \mathrm{~h}$ up to $12 \mathrm{~h}$ and then $24 \mathrm{~h}$ after surgery. An additional patient satisfaction questionnaire of the overall analgesic technique was completed $24 \mathrm{~h}$ after surgery (very satisfied, satisfied, adequate, unsatisfied, very satisfied).

The primary objective of this study was to determine whether an IV PCA with the ramosetron and tramadol combination was not inferior to tramadol alone for postoperative pain management. Based on a previous study [6], the cumulative $24 \mathrm{~h}$ consumption of tramadol was calculated as $1,388( \pm 340)$ and $703( \pm 266) \mathrm{mg}$ in the ramosetron and normal saline groups, respectively. The $95 \%$ lower limit of the prespecified noninferiority margin (30\%) was $158.2 \mathrm{mg}$. The calculated sample size was 49 patients per study group with a type I error rate of 0.05 , with 55 patients per group, assuming a $10 \%$ dropout rate.

2.1. Statistical Analysis. Wilcoxon's rank sum tests for continuous variables were used for comparisons between ramosetron group and control group. And $\chi 2$ test and Fisher's exact test were used for categorical variables. The difference of cumulative tramadol consumption during the postoperative 24 hours between groups was used for noninferiority test. Statistical analysis was performed using SAS version 9.4 (SAS Institute, Inc., Cary, NC, USA). A $p$ value of $<0.05$ was taken to indicate statistical significance.

\section{Results}

This study recruited 110 patients in total, 10 of whom (4 in the normal saline group, 6 in the ramosetron group) were excluded because of missing data, conversion to open surgery, or stopping of the IV PCA due to persistent nausea (Figure 1). There were no significant group differences in the demographic data, ASA physical status, operation time, or the amount of remifentanil and propofol used (Table 1).

Groups $\mathrm{R}$ and $\mathrm{N}$ received, respectively, $88 \pm 55$ vs. $79 \pm$ $42 \mathrm{mg}$ tramadol $(\mathrm{P}=0.511)$ after $1 \mathrm{~h}, 211 \pm 122$ vs. $198 \pm 109$ mg cumulative tramadol $(\mathrm{P}=0.610)$ after $4 \mathrm{~h}, 244 \pm 150$ vs. $231 \pm 134 \mathrm{mg}$ cumulative tramadol $(\mathrm{P}=0.793)$ after $8 \mathrm{~h}, 250$ \pm 156 vs. $247 \pm 153 \mathrm{mg}$ cumulative tramadol $(\mathrm{P}=0.972)$ after $12 \mathrm{~h}$, and $294 \pm 190$ vs. $284 \pm 178 \mathrm{mg}$ cumulative tramadol $(\mathrm{P}=0.791)$ after $24 \mathrm{~h}$, postsurgery (Figure 2$)$. Tramadol plus ramosetron was not significantly inferior to tramadol alone in alleviating the postoperative pain, since the upper and lower limits of the $95 \%$ CI of the $24 \mathrm{~h}$ cumulative tramadol difference were 83.34 and -63.93 and the lower limit of the 


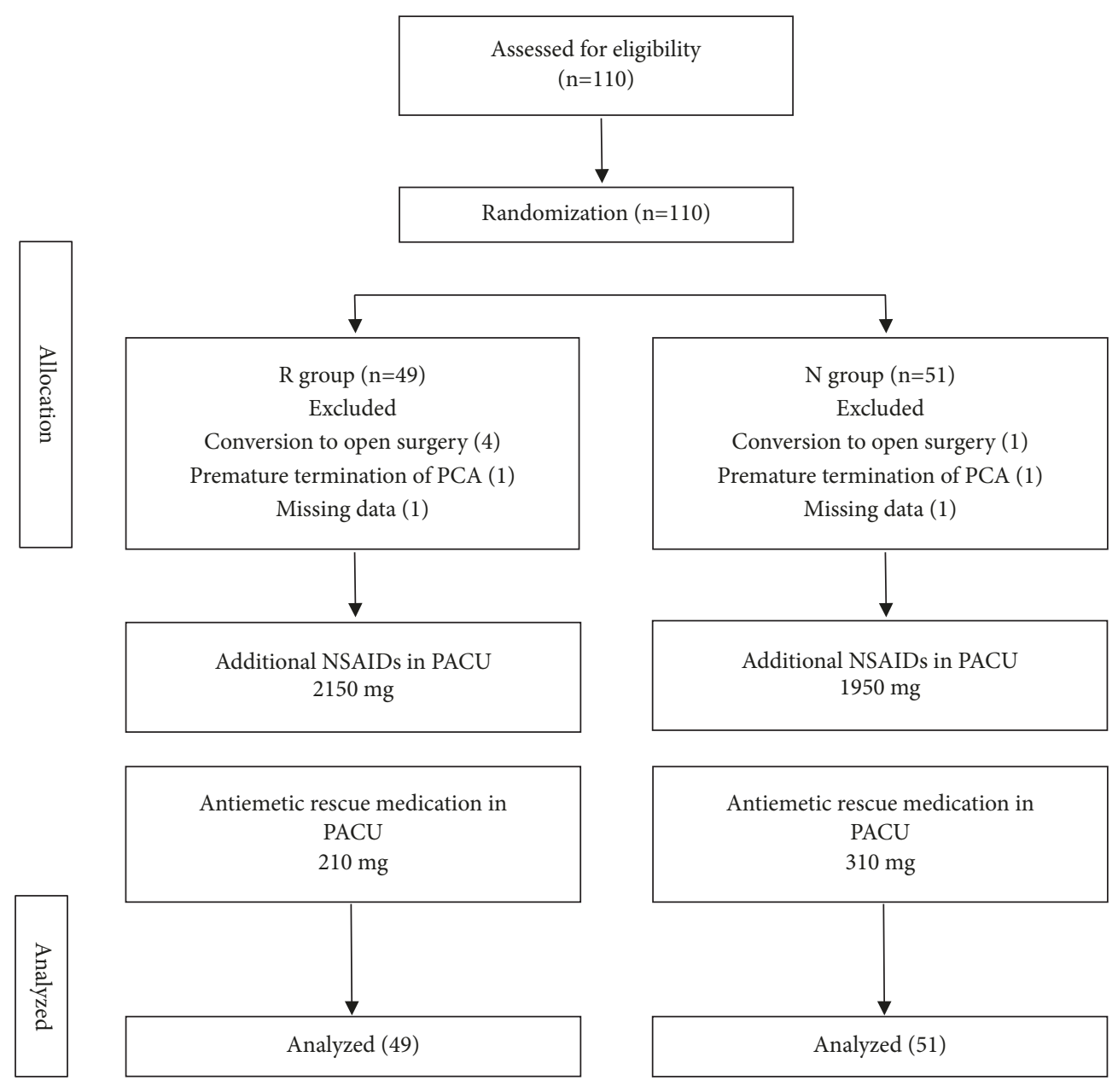

Figure 1: Study flow diagram.

95\% CI was above the predetermined lower noninferiority margin (-85.20) for the $24 \mathrm{~h}$ cumulative tramadol difference. Furthermore, there were no significant group differences in pain scores (at rest and during movement) during the study period (Figure 3 ). The nausea scores $(0 / 1 / 2 / 3) 1 \mathrm{~h}$ after surgery were $89.8 / 8.16 / 2.04 / 0 \%$ and $94.12 / 3.92 / 1.96 / 0 \%$ in the $\mathrm{R}$ and $\mathrm{N}$ groups, respectively $(\mathrm{P}=0.437)$. The nausea scores $(0 / 1 / 2 / 3) 24 \mathrm{~h}$ after surgery were $55.10 / 14.29 / 22.45 / 8.16 \%$ and $45.10 / 13.72 / 35.29 / 5.88 \%$ in the $\mathrm{R}$ and $\mathrm{N}$ groups, respectively $(\mathrm{P}=0.343)$. No group differences were observed in nausea scores (Table 1). The total fentanyl dose was slightly lower in the R group (2150 mg) compared to $\mathrm{N}$ group (1950 mg) in PACU, but this difference was not significant $(\mathrm{P}=0.313)$. A single rescue dose of Trolac $30 \mathrm{mg}$ was given to three patients in $\mathrm{R}$ group and two patients in $\mathrm{N}$ group in ward. The total metoclopramide dose was slightly lower in the R group (210 mg) compared to $\mathrm{N}$ group (310 $\mathrm{mg}$ ) in PACU, but this difference was not significant $(\mathrm{P}=0.437)$.

Furthermore, patient satisfaction with postoperative pain management did not differ between the two groups. No patient complained of headache, dizziness, or skin flushing, adverse effects known to occur with $5-\mathrm{HT}_{3}$ receptor antagonists.

\section{Discussion}

This randomized, controlled trial showed that simultaneous use of ramosetron did not affect tramadol's analgesic action during postoperative pain management. In a previous trial, Kim et al. [9] reported no antagonistic effects between ramosetron and tramadol, similar to our results.

Satisfactory postoperative analgesia is very essential because it results in faster recovery of pulmonary function, early ambulation, and shorter hospital stays [11]. PCA allows patients to manage their pain well; continuous infusion of analgesics with an initial loading dose is very useful to achieve patient satisfaction [12]. The effect of IV PCA tramadol has been demonstrated to be similar to that of PCA morphine following major surgery [13]. Tramadol is associated with less euphoria and addiction, because it exerts a markedly weaker $\mu$-agonist effect compared with morphine [14]. Houmes et al. [15] also reported less respiratory depression with tramadol, although the incidence of nausea and vomiting was higher. At present, 5- $\mathrm{HT}_{3}$ antagonists are the most widely used antiemetics for preventing PONV. Adding a 5- $\mathrm{HT}_{3}$ antagonist to tramadol IV PCA regimen would reduce nausea and vomiting. However, negative effects of $5-\mathrm{HT}_{3}$ antagonists on 
TABLE 1: Patients' characteristics and anesthesia data.

\begin{tabular}{|c|c|c|c|c|}
\hline & & Ramosetron $(n=49)$ & Control $(n=51)$ & P value \\
\hline & & $\mathrm{N}(\%)$ or $\mathrm{m}$ & $1-\max )$ & \\
\hline Age (years) & & $47(23-60)$ & $46(24-64)$ & $0.893^{\mathrm{W}}$ \\
\hline Weight (Kg) & & $55(45-70)$ & $57(46-101)$ & $0.324^{\mathrm{W}}$ \\
\hline Duration of surgery (min) & & $95(30-220)$ & $105(30-380)$ & $0.541^{\mathrm{W}}$ \\
\hline Duration of anesthesia (min) & & $130(60-285)$ & $145(65-420)$ & $0.638^{\mathrm{W}}$ \\
\hline Amount of infused remifentanil & & $496.5(206-1334)$ & $527(161-2088)$ & $0.526^{\mathrm{w}}$ \\
\hline Amount of infused propofol & & $945(190-2800)$ & $1160(481-3515)$ & $0.169^{\mathrm{W}}$ \\
\hline PONV scores $1 \mathrm{~h}$ postoperatively & 0 & $44(89.8)$ & $48(94.1)$ & $0.713^{\mathrm{F}}$ \\
\hline & 1 & $4(8.2)$ & $2(3.9)$ & \\
\hline & 2 & $1(2.0)$ & $1(2.0)$ & \\
\hline PONV scores $24 \mathrm{~h}$ postoperatively & 0 & $27(55.1)$ & $23(45.1)$ & $0.542^{\mathrm{F}}$ \\
\hline & 1 & $7(14.3)$ & $7(13.7)$ & \\
\hline & 2 & $11(22.4)$ & $18(35.3)$ & \\
\hline & 3 & $4(8.2)$ & $3(5.9)$ & \\
\hline ASA & Status I & $40(81.6)$ & $32(62.7)$ & $0.036^{\mathrm{C}}$ \\
\hline & Status II & $9(18.4)$ & $19(37.3)$ & \\
\hline Satisfaction & dissatisfied & $1(2.0)$ & $2(4.0)$ & $0.881^{\mathrm{F}}$ \\
\hline (missing =1) & neutral & $13(26.5)$ & $12(24.0)$ & \\
\hline & satisfied & $24(49.0)$ & $27(54.0)$ & \\
\hline & very satisfied & $11(22.5)$ & $9(18.0)$ & \\
\hline
\end{tabular}

C: Chi square test, F: Fisher's exact test, W: Wilcoxon rank sum test, PONV: postoperative nausea and vomiting, satisfaction for the overall analgesic technique.

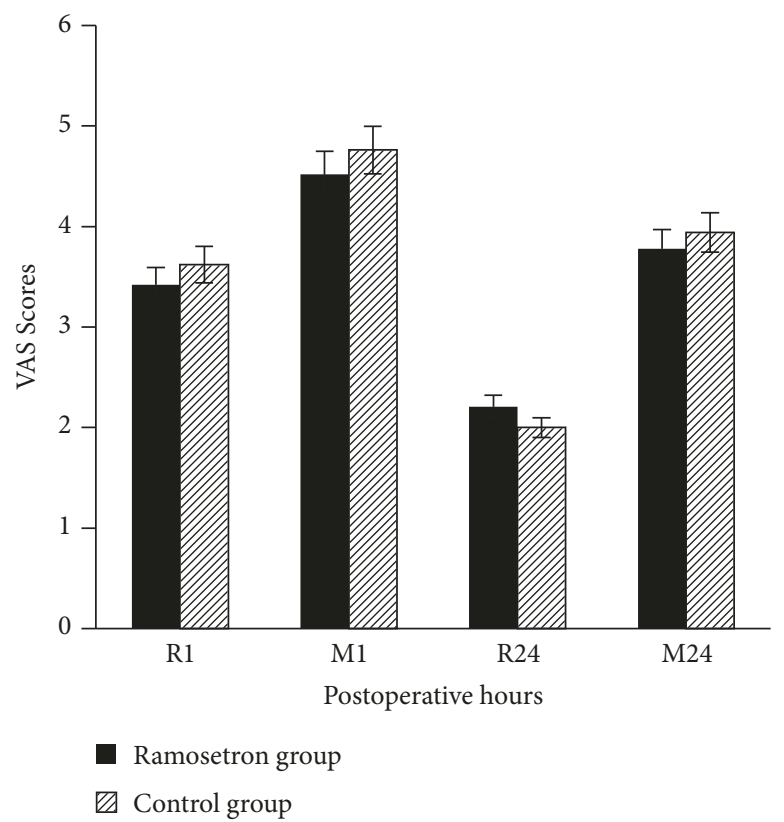

FIgURE 2: VAS scores in the postoperative $24 \mathrm{~h}$. There were no differences between groups during the study period. R1: VAS score in the postoperative $1 \mathrm{~h}$ during movement, M1: VAS score in the postoperative $1 \mathrm{~h}$ during rest, R24: VAS score in the postoperative $24 \mathrm{~h}$ during rest, M24: VAS score in the postoperative $24 \mathrm{~h}$ during movement.

the analgesic efficacy of tramadol have been reported [6-8]. For this reason, drug interaction must be considered. The mono o-desmethyl metabolite (M1) of tramadol has its analgesic effects. M1 metabolites are formed largely by CYP2D6

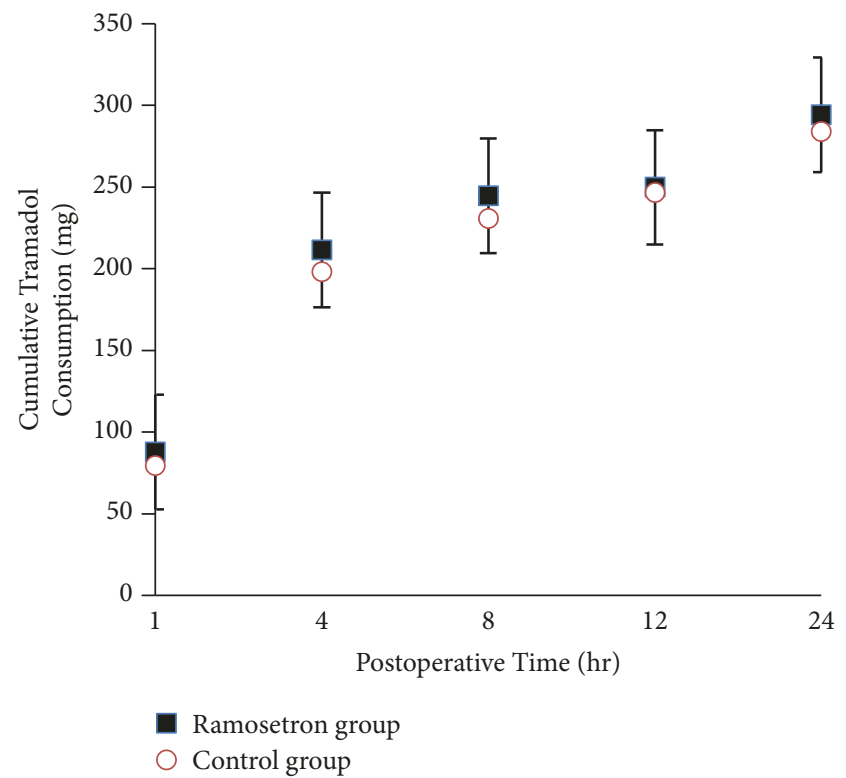

FIGURE 3: Cumulative tramadol consumption during the postoperative 24 hours.

activity, and serotonin receptor antagonists are also metabolized by CYP2D6 isoenzyme [16, 17]. Therefore, simultaneous administration of these drugs causes competition for CYP2D6 and affects the pharmacokinetics of ondansetron and tramadol. However, an interaction between tramadol and ramosetron could be less affected by pharmacokinetics since it had been reported that ramosetron does not cause 
clinically important CYP-mediated drug interactions in vivo and ramosetron undergoes metabolism by CYP1A2 [18]. In various clinical trials, ramosetron has been shown to have a more potent and longer antiemetic effect compared to ondansetron $[19,20]$. Roh et al. [21] demonstrated that ramosetron is superior to palonosetron, the most-recent 5$\mathrm{HT}_{3}$ antagonist, for preventing PONV with intravenous PCA, despite palonosetron having greater receptor affinity and a longer duration of action. Moreover, Kim et al. [9] showed that a single dose of ramosetron had no antagonist effect against tramadol.

The dose of ramosetron used in the present study was selected based on a previous study $[22,23]$. We coadministered $0.6 \mathrm{mg}$ of ramosetron with intravenous-tramadol IV PCA to prevent PONV. Few studies have examined the efficacy of ramosetron combined with IV PCA for preventing PONV. Choi et al. [22] reported that adding ramosetron to PCA effectively reduced the incidence of PONV during the first $48 \mathrm{~h}$ after surgery. Kim et al. [23] reported that a single dose of ramosetron $(0.3 \mathrm{mg})$ followed by ramosetron $(0.6 \mathrm{mg})$ mixed with PCA significantly decreased PONV compared with a single dose of ramosetron $(0.3 \mathrm{mg})$. Ogata et al. [24] reported that the $5-\mathrm{HT}_{3}$ receptor occupancy of ramosetron diminished to $50-60 \% 24 \mathrm{~h}$ after a single injection of ramosetron, and continuous infusion of ramosetron after a bolus dose would maintain a higher $5-\mathrm{HT}_{3}$ receptor occupancy level. In the present study, we used no loading dose of ramosetron before starting PCA, because we wanted to investigate the analgesic effect of tramadol with continuous coadministration of ramosetron. If we had administrated ramosetron before a loading dose of tramadol, a significant group difference in PONV incidence may have arisen.

This study had several limitations. First, we failed to reduce the nausea score and total antiemetic dose in group R. This might be explained by the fact that an emetogenic effect of tramadol involving the $5-\mathrm{HT}_{3}$ receptor is expected to be most pronounced during a loading dose of tramadol. In clinical settings, patients generally tend to discontinue PCA demands if they notice a distinct correlation between PCA doses and emesis [25]. Furthermore, the power analysis was based on cumulative consumption of tramadol. Thus, the sample size was insufficient: a larger number of patients are required to assess the antiemetic efficacy of ramosetron when coadministered with tramadol. Second, we did not know the optimal dose of ramosetron for combined use with PCA. Further studies are needed to evaluate the optimal administration dose of ramosetron with intravenous PCA. Third, we used a single-blinded study design, in which investigators unblinded to the treatment received by each group assessed the pain and nausea scores, rescue antiemetic doses, and patient satisfaction. Lastly, we did not give a loading dose of ramosetron before starting the PCA, so it is unclear whether ramosetron has reached a sufficient concentration to cause drug interaction with tramadol.

In conclusion, continuous administration of ramosetron did not decrease the analgesic action of tramadol. Therefore, we concluded that ramosetron will not affect dose of tramadol.

\section{Data Availability}

The data used to support the findings of this study are included within the article.

\section{Conflicts of Interest}

The authors declare that they have no conflicts of interest.

\section{References}

[1] M. A. Hadi, H. S. Kamaruljan, A. Saedah, and N. M. N. Abdullah, "A comparative study of intravenous patient-controlled analgesia morphine and tramadol in patients undergoing major operation," Medical Journal of Malaysia, vol. 61, no. 5, pp. 570576, 2006.

[2] K. F. J. Ng, T. S. T. Yuen, and V. M. W. Ng, "A comparison of postoperative cognitive function and pain relief with fentanyl or tramadol patient-controlled analgesia," Journal of Clinical Anesthesia, vol. 18, no. 3, pp. 205-210, 2006.

[3] R.-J. M. Houmes, M. A. Voets, A. Verkaaik, W. Erdmann, and B. Lachmann, "Efficacy and safety of tramadol versus morphine for moderate and severe postoperative pain with special regard to respiratory depression," Anesthesia \& Analgesia, vol. 72, pp. 510-514, 1992.

[4] M. Silvasti, N. Svartling, M. Pitkanen, and P. H. Rosenberg, "Comparison of intravenous patient-controlled analgesia with tramadol versus morphine after microvascular breast reconstruction," European Journal of Anaesthesiology, vol. 17, no. 7, pp. 448-455, 2000.

[5] E. A. Shipton, “Tramadol-present and future," Anaesthesia and Intensive Care, vol. 28, no. 4, pp. 363-374, 2000.

[6] R. Arcioni, M. Della Rocca, S. Romanò, R. Romano, P. Pietropaoli, and A. Gasparetto, "Ondansetron inhibits the analgesic effects of tramadol: a possible $5-\mathrm{HT}_{3}$ spinal receptor involvement in acute pain in humans," Anesthesia \& Analgesia, vol. 94, no. 6, pp. 1553-1557, 2002.

[7] Z. Cubukcu, H. Ozbek, Y. Gunes, M. Gunduz, D. Ozcengiz, and G. Isik, "Effect of ondansetron in lower extremity bone surgery on morphine and tramadol consumption using patient controlled analgesia," Agri, vol. 19, pp. 36-41, 2007.

[8] J. L. De Witte, B. Schoenmaekers, D. I. Sessler, and T. Deloof, "The analgesic efficacy of tramadol is impaired by concurrent administration of Ondansetron," Anesthesia \& Analgesia, vol. 92, no. 5, pp. 1319-1321, 2001.

[9] Y. Kim, D. Kim, T. Oh, E. Seo, and J. Ryu, "The influence of ramosetron on the analgesic effect of tramadol," Journal of Anesthesia and Clinical Research, vol. 5, pp. 483-485, 2014.

[10] D. Woo Han, S. Won Hong, J. Kwon, J. Woo Lee, and K. Jun Kim, "Epidural ondansetron is more effective to prevent postoperative pruritus and nausea than intravenous ondansetron in elective cesarean delivery," Acta Obstetricia et Gynecologica Scandinavica, vol. 86, no. 6, pp. 683-687, 2007.

[11] U. A. Bhosale, R. Khobragade, C. Naik, R. Yegnanarayan, and J. Kale, "Postoperative pharmacodynamic interaction of ondansetron; a 5-HT3 antagonist and paracetamol in patients operated in the ENT department under local anesthesia," Journal of Basic and Clinical Pharmacy, vol. 5, no. 3, pp. 84-86, 2014.

[12] S. Prakash, T. Fatima, and M. Pawar, "Patient-controlled analgesia with fentanyl for burn dressing changes," Anesthesia \& Analgesia, vol. 99, pp. 552-555, 2004. 
[13] K. A. Lehmann, U. Kratzenberg, B. Schroeder-Bark, and G. Horrichs-Haermeyer, "Postoperative patient-controlled analgesia with tramadol: analgesic efficacy and minimum effective concentrations," The Clinical Journal of Pain, vol. 6, no. 3, pp. 212-220, 1990.

[14] R. K. Stoelting, "Opioid agonists and antagonists," in Pharmacology and Physiology in Anesthetic Practice, pp. 69-101, JB Lippincott company, Philadelphia, Pennsylvania, 1987.

[15] R.-J. M. Houmes, M. A. Voets, A. Verkaaik, W. Erdmann, and B. Lachmann, "Efficacy and safety of tramadol versus morphine for moderate and severe postoperative pain with special regard to respiratory depression," Anesthesia \& Analgesia, vol. 74, no. 4, pp. 510-514, 1992.

[16] S. Grond and A. Sablotzki, "Clinical pharmacology of tramadol," Clinical Pharmacokinetics, vol. 43, no. 13, pp. 879-923, 2004.

[17] N. Rawal, R. Allvin, A. Amilon, T. Ohlsson, and J. Hallén, "Postoperative analgesia at home after ambulatory hand surgery: a controlled comparison of tramadol, metamizol, and paracetamol," Anesthesia \& Analgesia, vol. 91, pp. 347-351, 2001.

[18] T. Niwa, S. Yamamoto, M. Saito et al., "Effects of serotonin-3 receptor antagonists on cytochrome P450 activities in human liver microsomes," Biological \& Pharmaceutical Bulletin, vol. 29, no. 9, pp. 1931-1935, 2006.

[19] X. Rabasseda, "Ramosetron, a 5-HT3 receptor antagonist for the control of nausea and vomiting," Drugs of Today, vol. 38, no. 2, pp. 75-89, 2002.

[20] W. O. Kim, B. N. Koo, Y. K. Kim, and H. K. Kil, "Ramosetron for the prevention of postoperative nausea and vomiting (PONV): a meta-analysis," Korean Journal of Anesthesiology, vol. 61, no. 5, pp. 405-412, 2011.

[21] G. U. Roh, S. Y. Yang, J. K. Shim, and Y. L. Kwak, "Efficacy of palonosetron versus ramosetron on preventing opioid-based analgesia-related nausea and vomiting after lumbar spinal surgery," The Spine Journal, vol. 39, no. 9, pp. E543-E549, 2014.

[22] D. K. Choi, J. H. Chin, E. H. Lee et al., "Prophylactic control of post-operative nausea and vomiting using ondansetron and ramosetron after cardiac surgery," Acta Anaesthesiologica Scandinavica, vol. 54, no. 8, pp. 962-969, 2010.

[23] S.-H. Kim, C.-S. Oh, and S. J. Lee, "Efficacy of palonosetron and ramosetron on postoperative nausea and vomiting related to intravenous patient-controlled analgesia with opioids after gynecological laparoscopic surgery (double-blinded prospective randomized controlled trial)," Journal of Anesthesia \& Clinical Research, vol. 29, no. 4, pp. 585-592, 2015.

[24] A. Ogata, Y. Yamada, M. Sugiura, R. Takayanagi, Y. Sawada, and T. Iga, "Analysis of 5-HT 3 receptor antagonist, ramosetron hydrochloride, based on receptor occupancy considering its active metabolite," Yakugaku Zasshi, vol. 121, no. 11, pp. 793-798, 2001.

[25] N. I. Rauers, F. Stüber, E. Lee et al., "Antagonistic effects of ondansetron and tramadol? a randomized placebo and active drug controlled study," The Journal of Pain, vol. 11, no. 12, pp. 1274-1281, 2010. 


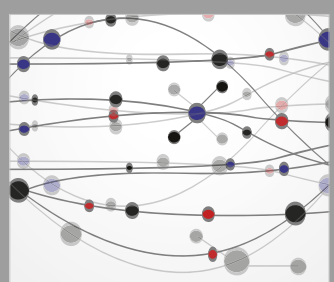

The Scientific World Journal
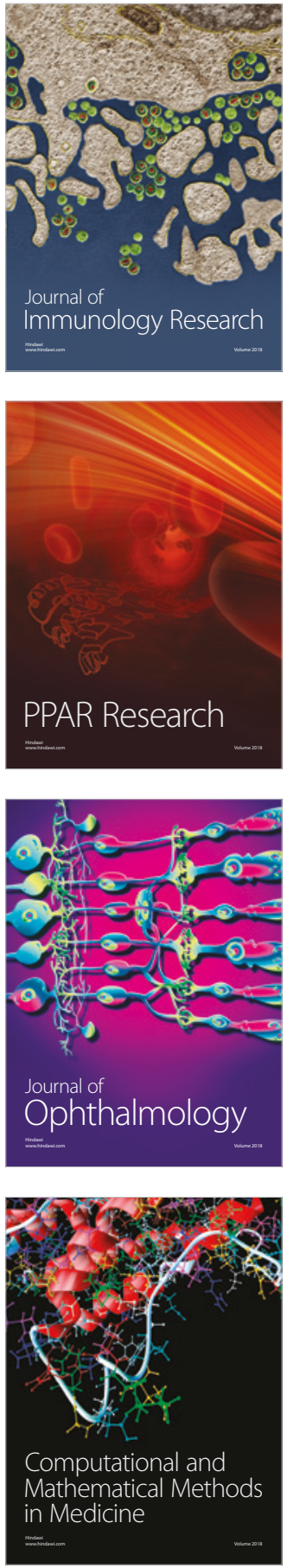

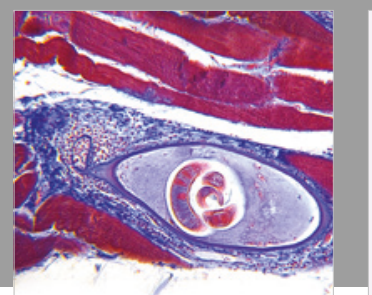

Gastroenterology Research and Practice

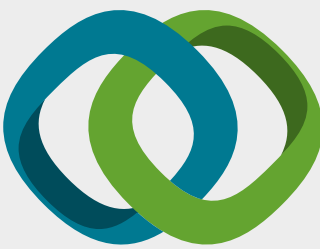

\section{Hindawi}

Submit your manuscripts at

www.hindawi.com
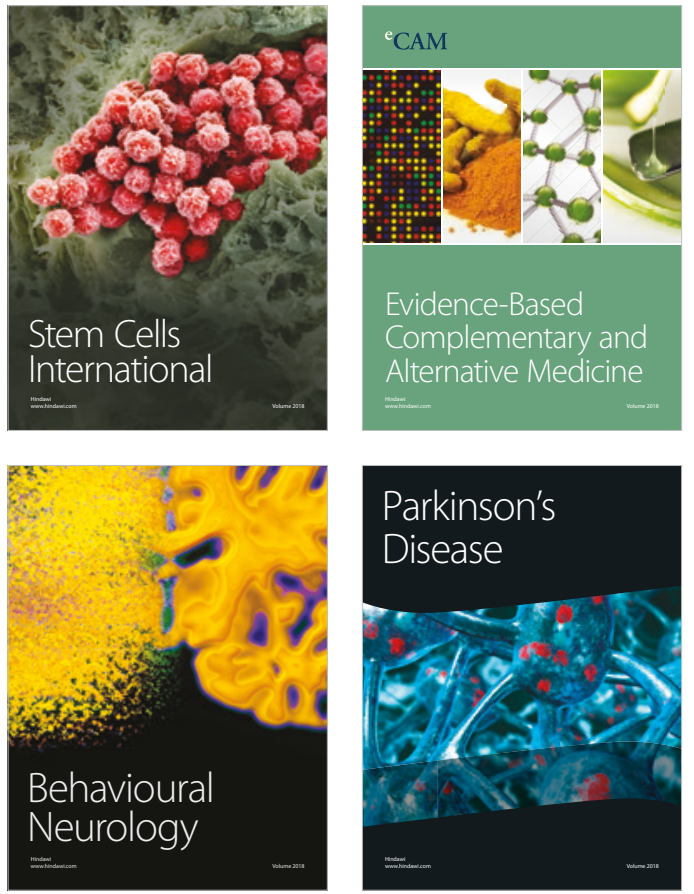

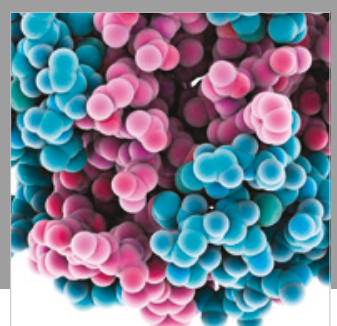

ournal of

Diabetes Research

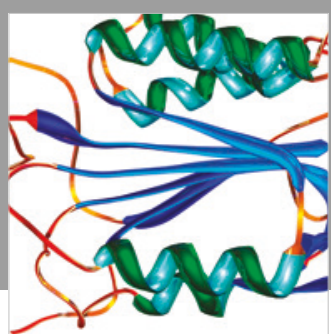

Disease Markers
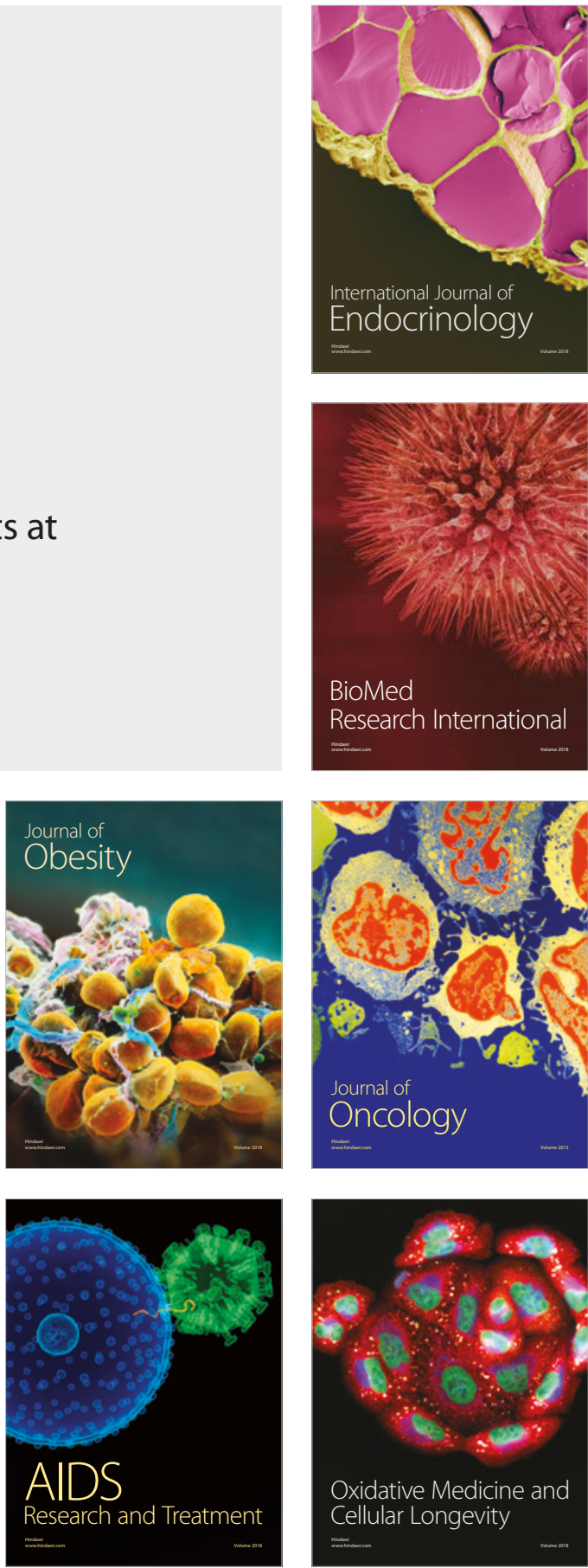